\title{
Trends and Causes of Traffic Accidents in Dubai
}

\author{
Akmal Abdelfatah ${ }^{1}$, Mohamed Saif Al-Zaffin ${ }^{2}$ and Waleed Hijazi ${ }^{1}$ \\ 1. Civil Engineering Department, American University of Sharjah, Sharjah 26666, United Arab Emirates \\ 2. General Department of Traffic Police, Dubai Police, Dubai 1493, United Arab Emirates
}

\begin{abstract}
This paper investigates the traffic accidents' trends and causes in Dubai. For this purpose, the traffic accident statistics for years 2003 to 2012 are used to examine the trends of different types of accidents and the causes of these accidents. Also, the paper determines the most common types of accidents over the study period and identifies some of the causes for these accidents. Furthermore, the paper shows the impact of the new traffic law amendments, which were issued in 2008, on the accident rates and trends. The results showed that the implementation of the traffic law amendments did not have major impact in year 2008. However, there was a significant effect of these amendments in the following years. Also, lack of awareness of traffic laws and regulations in Dubai has been proven to be one of the major causes of accidents. Finally, the paper provides some recommendations to reduce the traffic accident rates, in order to achieve the Dubai Police Department 2020 strategic goal to have zero fatalities.
\end{abstract}

Key words: Traffic safety, accident causes, fatalities.

\section{Introduction}

Dubai has witnessed a very high population and economic growth rate over the past two decades. This increase was, unfortunately, accompanied by an increase in the traffic accident rates as well, which were higher than the rates observed in most of the western countries. Having a similar situation in most of the major cities in the UAE (United Arab Emirates), the government of UAE has recognized this increase and applied major amendments of the Federal Traffic Law as of March 2008. The new system implemented much higher penalties on traffic offences and introduced registration of traffic points even in absentia offenses unlike the previous system that registers traffic points only for spot offenses. In addition to these amendments, Dubai Police Department has declared that the strategic goal for Dubai is to have zero fatality per hundred thousand of population by the year 2020 .

\section{Literature Review}

There are several studies that deal with the rate of

Corresponding author: Akmal Abdelfatah, Ph.D., associate professor, research fields: transportation engineering and traffic analysis.E-mail: akmal@aus.edu. accidents and fatalities as related to the population or the number of vehicles registered in a certain city or country. In 2004, the WHO (World Health Organization) [1] reported that traffic accidents are the 9th cause of death, with a total number of deaths equal to 1.3 million. Lately, WHO showed that road accidents were the cause for 1.24 million fatalities worldwide. The data in the report were collected from 182 countries around the world and included about $99 \%$ of the world's population [2]. This shows the seriousness of the situation and the need for major efforts to improve the current systems which can result in decreasing the number of fatalities due to road accidents.

Other research efforts studied the road traffic accidents in China for the period 2000-2005. The research concluded that the driver experience, the classification of the road, and the level of urban development surrounding the road are the main factors that characterize the accidents' fatalities in China. In addition, there are other reasons that include: cultural issues such as drunk driving, poor road performance that is due to limited funding, overloaded heavy trucks because of expensive toll, resulting in more sever 
fatalities and lack of safety. It suggested allocating fund for investments in transportation infrastructure that is not only beneficial to traffic but also to the national GDP (gross domestic product). Furthermore, the road traffic safety system in China needs to be enhanced [3, 4]. Peng et al. [5] considered the traffic accidents in urban areas in China, where the population growth is causing higher frequency of traffic accidents. They utilized a database that includes historical data regarding road traffic accidents in Shanghai. The data were studied in order to determine the relationship between traffic accidents and the road parameters. They also provided recommendations to the local authorities in order to improve the traffic safety on local roads. Another research evaluated the characters and causes of accidents migration in south China [6].

Another important reason for road traffic accidents is related to the driver behaviour. The attitude of the drivers was examined through surveying 2,614 drivers in Norway. The questionnaire results indicated that behaviours such as speeding and rule violations, careless driving, attitude towards drinking and driving are among the most important behaviours that impact the involvement in accidents. It was also concluded that age and gender are significant factors that impact the variations of drivers' attitude [7].

Erdogan [8] evaluated the situation in Turkey using the accident data for 2001-2006 and concluded that although there is a decrease in fatalities, the fatalities ratio is still high when compared to developed countries. There are many improvements that could be applied to the transportation system in terms of safety to decrease fatalities.

As a result of a study on the rural Sweden roads, it was mentioned that the presented data should consider many factors such as environmental issues, and the type of the traffic flow, for instance, to be homogeneous (light vehicles only) or nonhomogeneous (light and heavy vehicles). The study developed empirical models describing the relationships between accident frequency and traffic flow. The results concluded that the consideration of homogeneous or nonhomogeneous traffic has a significant impact on the accidents' trends [9]. A similar study used regression analysis to evaluate the traffic accident data in Jordan and the UAE from 1990 till 2004, and Qatar till 2006. The study results indicated that exponential models showed the best fit to predict the relationship between number of fatalities and the population or number of vehicles. The models showed an acceptable average absolute error of $20.9 \%$ for Qatar, $10.9 \%$ for Jordan and $5.5 \%$ for the UAE. Also, the authors concluded that the gross domestic income and the fatality rate showed a strong linear relationship [10]. The effect of driver's age on traffic accidents in Florida US has been studied by Abdel-Aty et al. [11]. The authors used the 1994 and 1995 traffic accident data in Florida to develop log-linear and logit models. These models considered the relationship between the driver's age and several factors that impact traffic accidents, such as traffic volume, severity of the injury, types of collision, road type, and speed distribution.

As a way to decrease the number of accidents, approach traffic calming processes have been studied by Knapp [12]. The speed-control measures are controlled by three ways: vertical speed control, horizontal speed control and narrowing. Vertical speed control includes humps placed across the roadway. On the other hand, the horizontal speed control is placed on the road to force the driver to change direction in order to pass it. The narrowing includes the curb extension that reduces space in which a car can pass through.

In conclusion, it is clear that the traffic accidents are causing major problems in different parts of the world. Many of the reasons for accidents that have been reported in the literature are applicable to Dubai, such as speeding, rule violations, and careless driving. However, some of the most common reasons for accidents in China and Europe are not very common in Dubai, such as drunk driving. As for the road conditions, it is not a major problem in Dubai as most 
of the roads are fairly new and have been designed and constructed according to the international standards.

\section{Data Collection}

The data collected in this paper are from different sources. The number of accidents and population from 2003 till 2012, and the number of registered vehicles from 2003 till 2005 are provided by the General Department of Traffic Police, Dubai Police. The number of registered vehicles in Dubai from 2006 till 2012 is obtained from RTA (Road and Transportation Authority).

\section{Research Methodology}

The research is aiming at using regression analyses to estimate the trend of accidents in Dubai. Two accident rates will be analysed: one based on population and the other is based on number of registered vehicles. Based on the regression analyses, the research recommends more reliable rate to be used for accident analysis in Dubai. Furthermore, the research defines the most common types of accidents in Dubai and determines the general trend of these common types of accidents based on regression analysis.

\section{Analysis and Discussion}

Table 1 shows the total number of accidents, population, rate of accidents per 100,000 population, the number of registered vehicles, and the rate of accidents per 10,000 registered vehicles for years 2003 to 2012

Fig. 1 shows the data for the number of accidents per 100,000 population and the regression analysis results

Table 1 Traffic accident data of Dubai (2003-2012).

\begin{tabular}{llllcc}
\hline Year & Total number of accidents & Population & $\begin{array}{l}\text { Accidents per 100,000 } \\
\text { population }\end{array}$ & $\begin{array}{l}\text { Number of registered } \\
\text { vehicles }\end{array}$ & $\begin{array}{l}\text { Accidents per 10,000 } \\
\text { registered vehicles }\end{array}$ \\
\hline 2003 & 2,287 & $1,141,487$ & 200.4 & 435,722 & 52.5 \\
2004 & 2,413 & $1,228,178$ & 196.5 & 500,272 & 630,000 \\
2005 & 2,794 & $1,321,453$ & 211.4 & 740,187 & 44.3 \\
2006 & 3,224 & $1,421,812$ & 226.8 & 868,592 & 33.6 \\
2007 & 3,335 & $1,529,792$ & 218.0 & 996,997 & 38.4 \\
2008 & 4,011 & $1,645,973$ & 243.7 & $1,021,880$ & 40.2 \\
2009 & 3,576 & $1,770,978$ & 201.9 & $1,031,961$ & 35.0 \\
2010 & 2,686 & $3,300,000$ & 81.4 & $1,055,412$ \\
2011 & 2,636 & $3,361,183$ & 78.4 & $1,137,750$ \\
2012 & 2,932 & $4,089,107$ & 71.7 & 26.0 \\
\hline
\end{tabular}

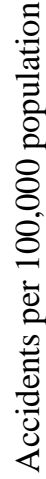
300.0

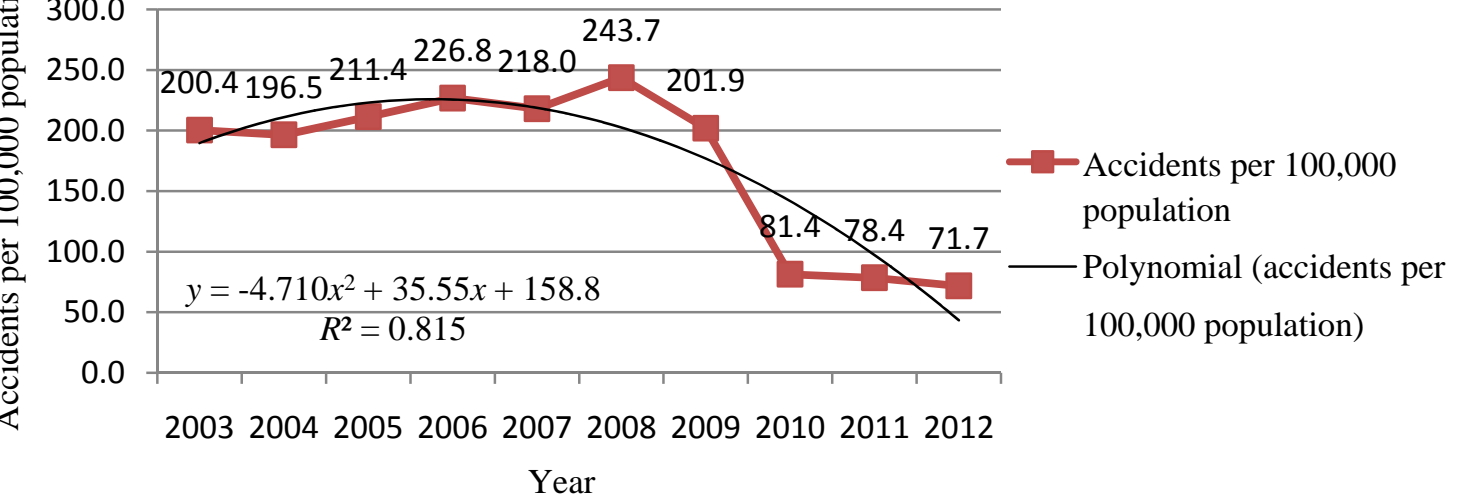

Fig. 1 Accidents per 100,000 population in Dubai (2003-2012). 
for the trend of accidents. The most suitable regression is a polynomial curve (second order) with a coefficient of determination $\left(R^{2}\right)$ value of about 0.82 . The regression analysis shows a good fit with the actual data.

Fig. 2 illustrates the rate of accidents per 10,000 registered vehicles in Dubai and the regression analysis results. It is clear that the linear regression for this case presents an excellent fit with an $R^{2}$ of about $95 \%$.

Considering the results shown in Figs. 1 and 2, it can be noticed that there is a general decreasing trend in the total number of accidents. As in Figs. 1 and 2, there is a significant reduction in the number of accidents between 2008 and 2009. This can be attributed to the application of the new traffic law that applied the traffic points' system. This system was announced in March 2008 and it authorizes police departments in UAE to withdraw a driving license when the drivers are involved in serious traffic violations. According to the new system, a driving license is withdrawn if the driver receives a total of 24 traffic points with a 12-month period. Some violations are penalized by 24 traffic points (such as drunk driving, driving a vehicle without a license plate, not stopping after causing an accident with injuries, and dangerous overtaking by trucks). Also, some other violations are considered serious as they result in a penalty of 12 points (such as dangerous driving "racing", reckless driving, speeding (driving 60 $\mathrm{km} / \mathrm{h}$ above the speed limit), running away from a policeman, and falling or leaking load for trucks). Consequently, the number of accidents is in decrease.

It seems that the use of the rate of accidents per 100,000 of the population might not be as good as the rate of accidents per 10,000 registered vehicles. This fact can be attributed to the fact that there is a large segment of the population in Dubai who are construction workers that do not travel a lot. This conclusion is drawn based on the regression analyses results. According to the equation shown in Fig. 1, the number of accidents per 100,000 population can reach 0 in year 2013, which is not realistic. However, the equation shown in Fig. 2 shows that the number of accidents is expected to be 0 (or practically a very small value) between 2019 and 2020, which is more acceptable.

Accidents in Dubai are classified into six categories as illustrated in Table 2. The accident categories are: (1) hitting a stationary object; (2) hitting a person; (3) flip over; (4) hitting an animal; (5) falling; (6) hitting a moving object (include accidents between two cars). Headings of Table 2 are given numbers that refer to previous sequence.

As shown in Table 2, the most common type of accidents is hitting a moving object that includes accidents between cars (Type 6). This represents more than $60 \%$ of the total accidents from 2003 till 2012, as

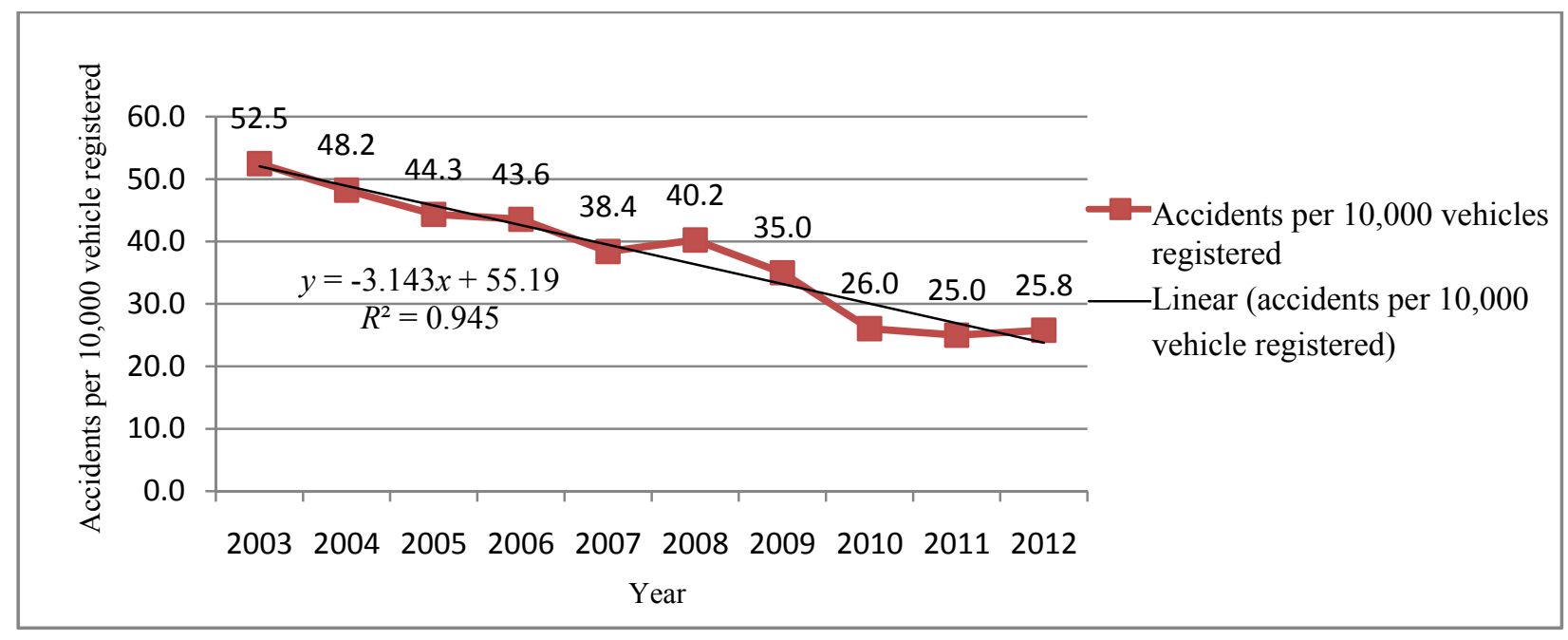

Fig. 2 Death per 10,000 registered vehicles in Dubai (2003-2012). 
Table 2 Types of accidents in Dubai (2003-2012).

\begin{tabular}{lllllllllllll}
\hline Year & Type 1 & $\begin{array}{l}\text { \% of } \\
\text { Type } 1\end{array}$ & Type 2 & $\begin{array}{l}\text { \% of } \\
\text { Type 2 }\end{array}$ & Type 3 & $\begin{array}{l}\text { \% of } \\
\text { Type 3 }\end{array}$ & Type 4 & $\begin{array}{l}\text { \% of } \\
\text { Type 4 }\end{array}$ & Type 5 & $\begin{array}{l}\text { \% of } \\
\text { Type 5 }\end{array}$ & $\begin{array}{l}\text { Type 6 } 6 \\
\text { \% of } \\
\text { Type 6 }\end{array}$ \\
\hline 2003 & 312 & 13.6 & 408 & 17.8 & 200 & 8.8 & 19 & 0.8 & 5 & 0.2 & 1,343 & 58.7 \\
2004 & 298 & 12.4 & 479 & 19.9 & 141 & 5.8 & 11 & 0.5 & 9 & 0.4 & 1,475 & 61.1 \\
2005 & 437 & 15.6 & 505 & 18.1 & 135 & 4.8 & 15 & 0.5 & 13 & 0.5 & 1,689 & 60.5 \\
2006 & 486 & 15.1 & 603 & 18.7 & 129 & 4.0 & 7 & 0.2 & 8 & 0.3 & 1,991 & 61.8 \\
2007 & 456 & 13.7 & 665 & 19.9 & 130 & 3.9 & 10 & 0.3 & 10 & 0.3 & 2,064 & 61.9 \\
2008 & 545 & 13.6 & 754 & 18.8 & 176 & 4.4 & 9 & 0.2 & 16 & 0.4 & 2,511 & 62.6 \\
2009 & 493 & 13.8 & 537 & 15.0 & 177 & 5.0 & 8 & 0.2 & 11 & 0.3 & 2,350 & 65.7 \\
2010 & 439 & 16.3 & 336 & 12.5 & 143 & 5.3 & 10 & 0.4 & 12 & 0.5 & 1,746 & 65.0 \\
2011 & 418 & 15.9 & 333 & 12.6 & 138 & 5.2 & 2 & 0.1 & 8 & 0.3 & 1,737 & 65.9 \\
2012 & 511 & 17.4 & 359 & 12.2 & 146 & 5.0 & 5 & 0.2 & 6 & 0.2 & 1,905 & 65.0 \\
\hline
\end{tabular}

Type 1: hitting a stationary object; Type 2: hitting a person; Type 3: flip over; Type 4: hitting an animal; Type 5: falling; Type 6: hitting a moving object (include accidents between two cars).

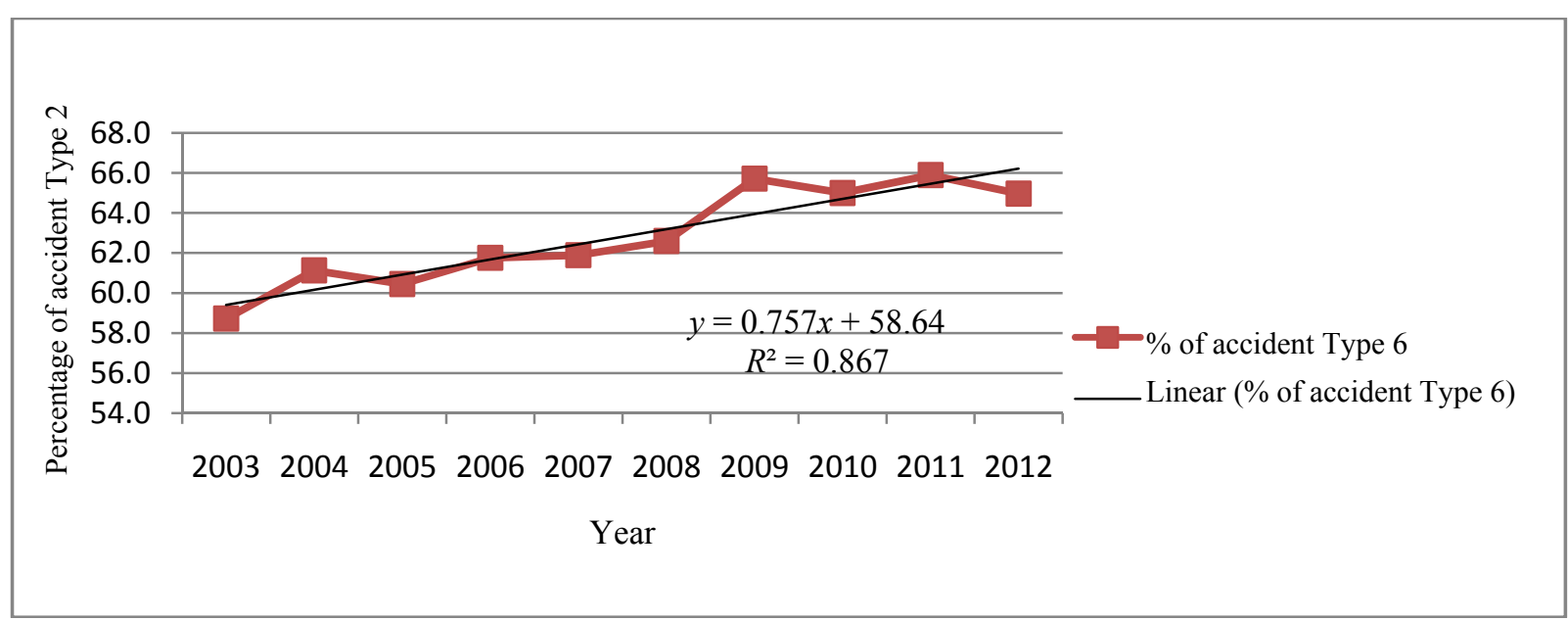

Fig. 3 Percentage of accidents due to hitting a moving object (2003-2012).

indicated in Fig. 3. The regression analysis for this type of accidents shows a very good fit with an $R^{2}$ of about 0.87 . Also, the trend is increasing, which indicates that the percentage for this type of accidents is increasing over years. The driving behaviour is the main cause of such accidents.

The second most common accident is hitting a person (Type 2) with a percentage of almost $17 \%$ of the total accidents, shown in Fig. 4. The regression analysis for this type of accidents resulted in a polynomial equation (second order) with an $R^{2}$ of about 0.82 . The trend of this type of accidents is decreasing. This can be attributed to the fact that the authorities in Dubai are implementing more physical restrictions to control the location of pedestrian crossings. Also, the fact that Dubai Traffic Police Department has conducted several awareness campaigns that targeted all types of road users including pedestrians has a significant contribution to the reduction in this type of accidents.

Finally, the third most common type of accidents is accident Type 1 (hitting a stationary object), which represents about $15 \%$ of the total number of accidents in Dubai. The trend for Type 1 accidents is depicted in Fig. 5. The regression analysis for this type did not show a strong fit as the $R^{2}$ is about 0.54 . However, the trend shows a slight increase in the percentage of these accidents. This type of accident is hitting a stationary object, which is caused by the bad drivers' behaviour.

These three most common types of accidents in Dubai represent about $95 \%$ of the total number of accidents. In addition to that, the two types of accidents 


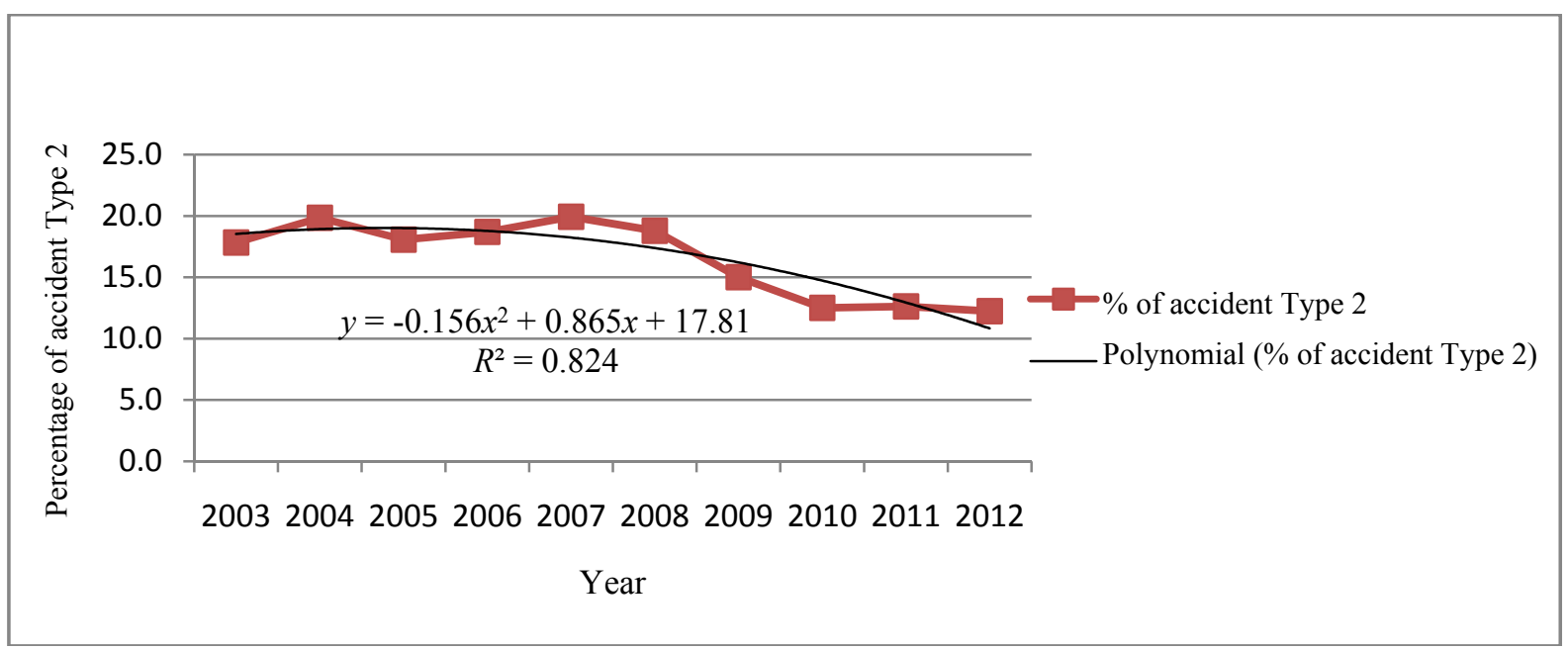

Fig. 4 Percentage of accidents due to hitting a person (2003-2012).

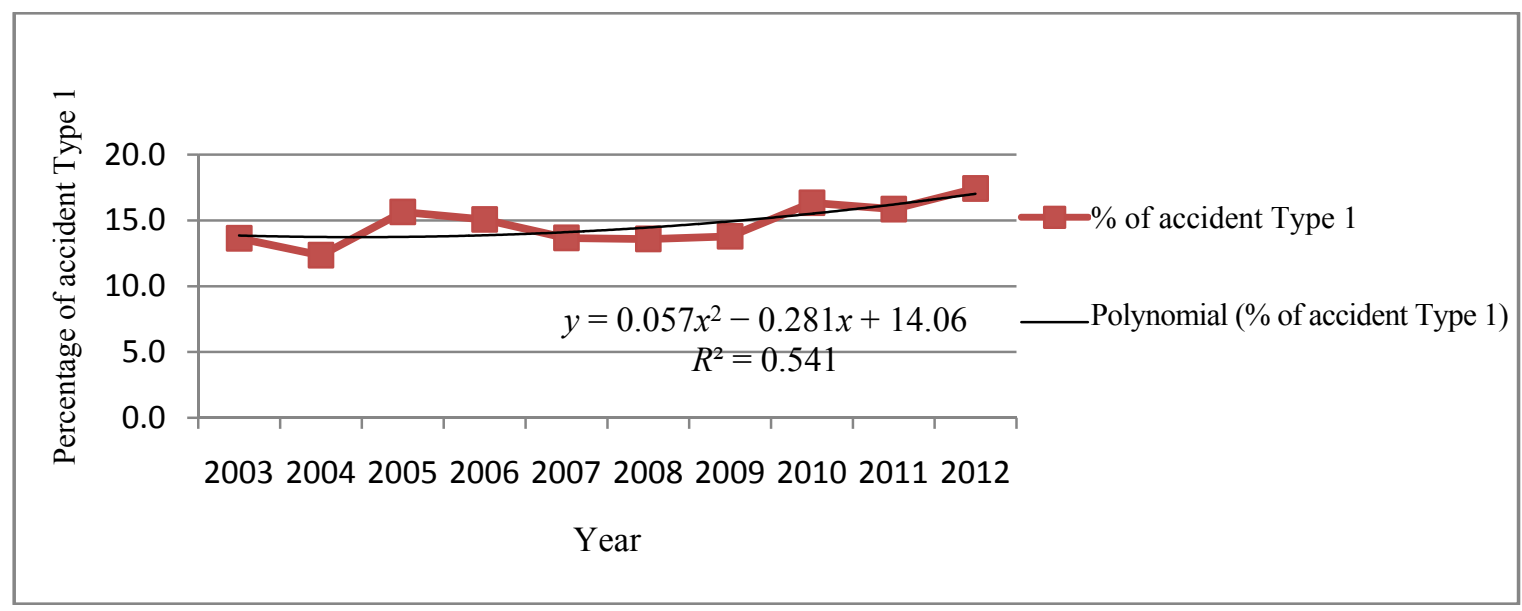

Fig. 5 Percentage of accidents due to hitting a stationary object (2003-2012).

that depend on the drivers' behaviour (Types 6 and 1) represent more than $80 \%$ of the total number of accidents in Dubai. This is an alarming sign that the Dubai Traffic Police Department has to consider when applying new strategies to improve the traffic safety on Dubai's roads. In contradiction to the trend of the Type 6 accidents, Type 2 accidents show a reducing trend.

\section{Future Work}

The authors are planning for some future work to expand this research. Some of the proposed future studies are:

- considering the rate of fatalities as an indicator of traffic safety on Dubai roads;

- investigating the distribution of the characteristics of drivers involved in the accidents;

- considering the number of traffic fines issued and examining its impact on the traffic safety.

\section{Conclusions}

The number of accidents is of a major concern to Dubai Government in general and to the Dubai Traffic Police Department in specific. The paper showed the trends of the total number of accidents and the most common types of accidents in Dubai. The total number of accidents has an increasing trend from 2003 to 2008, followed by a decreasing trend from 2009 till 2012, which is mainly due to the implementation of a new traffic law in Dubai. The reduction in accident rates as related to population and number of registered vehicles 
is a positive sign of an improved safety on Dubai roads. However, the rate of accidents per 10,000 registered vehicles is a more robust measure.

Furthermore, data show that there are different types of accidents where the most common one is hitting a moving object and then hitting a person followed by hitting a stationary object. The first and third common types mainly depend on driving skills, while the second type is influenced by both the driving skills and the awareness of the public. Therefore, Dubai authorities (RTA and Dubai Police Department) may consider some of the following recommendations to improve the traffic safety and help in reducing the accident rates further:

- apply stricter driving tests when issuing a new driving license. Also, whenever a driving license is withdrawn because of traffic violations, the driver has to go through a stricter training program. In addition to that, keeping track of the violations' records of these drivers in the future and applying tougher penalties on them might help in reducing the number of accidents;

- continue to conduct traffic awareness campaigns using different languages as the population in Dubai includes significant groups from different parts of the world;

- consider higher penalties for causing accidents, especially the accidents that are caused by the personal errors of the driver or pedestrian.

These suggestions may result in some improvements in the accidents' trends in Dubai.

\section{References}

[1] WHO. 2004. The Global Burden of Disease. Switzerland: WHO.
[2] WHO. 2013. Global Status Report on Road Safety 2013. WHO.

[3] Zhao, S. 2007. "Rapid Motorization and Road Traffic Accidents in China." In Proceedings of the 11th World Conference on Transportation Research [CD-ROM].

[4] Zhao, S. 2009. "Road Traffic Accidents in China." International Association of Traffic and Safety Sciences 33 (2): 125-7.

[5] Peng, C., Lu, J., and Yin, W. 2010. "An Empirical Study of the Urban Traffic Accident Causes with Correspondence Analysis Method." In Proceedings of the 10th International Conference of Chinese Transportation Professionals, 1299-306.

[6] Jiao, C., Yang, M., and Hao, Y. 2009. "Analysis of Characters and Causes of Road Traffic Accident Migration." In Proceedings of the 9th International Conference of Chinese Transportation Professionals, 662-8.

[7] Iversen, H., and Rundmo, T. 2004. "Attitudes towards Traffic Safety, Driving Behaviour and Accident Involvement among the Norwegian Public." Ergonomics 47 (5): 555-72.

[8] Erdogan, S. 2009. "Explorative Spatial Analysis of Traffic Accident Statistics and Road Mortality among the Provinces of Turkey." Journal of Safety Research 40 (5): 341-51.

[9] Hiselius, L. 2004. "Estimating the Relationship between Accident Frequency and Homogeneous and Inhomogeneous Traffic Flows." Accident Analysis and Prevention 36 (6): 985-92.

[10] Bener, A., Hussain, S. J., Al-Malki, M. A., Shotar, M. M., Al-Said, M. F., and Jadaan, K. S. 2010. "Road Traffic Fatalities in Qatar, Jordan and the UAE: Estimates Using Regression Analysis and the Relationship with Economic Growth." East Mediterranean Health Journal 16 (3): 318-23.

[11] Abdel-Aty, M., Chen, C., and Schott, J. 1998. "An Assessment of the Effect of Driver Age on Traffic Accident Involvement Using Log-Linear Models." Accident Analysis and Prevention 30 (6): 851-61.

[12] Knapp, K. 2000. "Traffic-Calming Basics." Civil Engineering-ASCE (American Society of Civil Engineers) 70 (1): 46-9. 